\title{
Understanding Weed Resistance as a Wicked Problem to Improve Weed Management Decisions
}

\author{
Raymond A. Jussaume, Jr. and David Ervin*
}

\begin{abstract}
Managing weed resistance has become a major challenge for many agricultural producers. Resistance is growing in terms of the number of weeds exhibiting resistance and the number of herbicides to which weeds are becoming resistant. The susceptibility of weeds to herbicides in many regions is a diminishing common pool resource affected by local producer weed control actions and natural conditions. Given the growing number of weeds exhibiting resistance, and the recognition that weed resistance is not a private property issue, we argue that managing resistance must be viewed as a wicked problem with no standard template across regions. Finding farm management approaches that help farmers successfully address weed resistance requires a shared perspective that incorporates an improved understanding of the human dimensions of weed management. Through an analysis of wicked problem characteristics, we argue that a people-centered approach to weed management is necessary. We offer principles learned from tackling other wicked agriculture and resource conservation issues to guide such approaches. Education, technical assistance, incentive schemes and regulatory efforts, and other strategies can play roles in constructing management approaches for herbicide resistance, but will have to vary from current efforts to unravel the mysteries of more effective weed management. Building a more inclusive approach, in terms of stakeholders and disciplines, will be key to achieving progress.
\end{abstract}

Key words: Herbicide resistance, weed management, people-centered, adaptive principles, full stakeholder involvement

Escalating weed resistance to herbicides is bringing significant social, environmental, and economic risks and challenges to the entire agricultural industry. Four hundred forty-nine unique cases of herbicide resistance (i.e., weed species by herbicide mechanism of action) have been documented, up from just five in 1975 (Heap 2015). More ominously, approximately 100 weed species around the globe are now resistant to more than one mechanism of action (Heap 2015). The vast majority of the increase has been since 1995 , and these trends are expected to continue indefinitely. As a result, growers are experiencing higher production costs and/or reduced yields; farm input suppliers and cropping advisers are faced with the challenge of supplying innovative weed management tools; and rural communities wonder what the social, economic, and environmental consequences will be. Policy makers also are facing the dilemma of whether to abandon voluntary education and technical assistance programs that have proven

\footnotetext{
DOI: $10.1614 /$ WS-D-15-00131.1

* Professor, Department of Sociology, Michigan State University, East Lansing, MI 48824; and Professor Emeritus, Economics and Environmental Management and Senior Research Faculty, Institute for Sustainable Solutions, Portland State University, Portland, OR 97201. Corresponding author's E-mail: jussaume@msu.edu
}

ineffective and move to more coercive private or public regulatory approaches.

Managing weed resistance, or for that matter any type of pest resistance to cropping practices, can be interpreted as a public-resource conservation challenge. For example, research based on theoretical models and game theory conducted on the topic of invasive species argues that invasive species are a type of public good (which in this case might be more appropriately termed a "public bad") in that they cannot be controlled solely through individual actions on private property (Fenichel et al. 2014; McCoy and Amatya 2005). Based on this, we assume that the susceptibility of weeds to effective control by herbicides, not to mention mechanical and cultural practices, is an exhaustible public resource. That resource becomes increasingly depleted as weeds develop resistance to an increasing array of herbicides. Particularly in cases where a specific herbicide/management strategy is used repeatedly and extensively, ecological conditions are created that select within a weed population for resistant biotypes that survive, reproduce, and spread. The rate at which those biotypes emerge depends on the diversity of weed control practices used (Owen and Boerboom 2004). Therefore, the rate at which the exhaustible resource (in this case, the weed gene pool susceptible to the herbicide) is 
depleted (i.e., the herbicide loses its effectiveness) depends on the degree to which the herbicide is utilized. The resource can be maintained for a longer period by use of a diverse, integrated set of weed management practices by multiple actors working in concert. Maintaining the public resource will not only be dependent on the accumulated actions of thousands of individuals, but also upon the ability of groups of individuals to act in tandem in order to ensure that resistance is addressed on a regional basis. In other words, the mobility of weeds necessitates community-based management approaches.

Conceptualizing weed management practices in general, and herbicides in particular, as a potentially exhaustible, and a socially shared, resource that necessitates, in part, socially based solutions, is not a common theme in the literature that examines some of the human dimensions of weed resistance. Llewellyn and Allen (2006), in a study conducted in Australia, provide empirical evidence that farmers there recognize the mobility problem of weeds, and Foresman and Glasgow (2008) reported on farmer perceptions of the existence of resistant weeds. Also, Edwards et al. (2014) provided data on weed management costs and crop yields in glyphosateresistant crop systems. However, none of these studies examined the underlying social factors that help explain differences in problem perception and attempted solutions, and more importantly for this manuscript, provide no insight into the interconnections between social and biophysical factors underlying the weed resistance problem.

The purpose of this paper is to help readers understand the full complexity of the weed resistance problem, and the need to develop socially shared weed management practices, by highlighting how weed resistance is a wicked problem (Batie 2008; Rittel and Weber 1973). We argue that comprehending herbicide resistance as a wicked problem is necessary for scientists and practitioners, who will need to use adaptive management principles collaboratively to explore the efficacy of an integrated set of alternative management approaches for managing weeds. To help develop this perspective, we expand on the notion of wicked problems to characterize the challenges before the weed science and farming communities. Several examples of the wickedness of actual herbicide resistance problems are offered to make the complexities more concrete. This is followed by a presentation of 10 principles that can guide a process to negotiate wicked problems, which in the context of weed management we argue needs to contain a community-based element. Unlike traditional weed management programs that focus on technical matters, such as herbicide selection, the principles emphasized in this article argue that a people-centered approach that uses a wide array of practices will be necessary, although not sufficient, to make progress. We note where different approaches to weed management, such as education and technical assistance, incentive schemes, and regulatory efforts, may play roles in the negotiation of constructive approaches to herbicide resistance. We conclude by offering suggestions for implementing new research and action programs that may help unravel the mysteries of more effective weed management.

\section{Digging into Wicked Problems}

The underlying premise of this article, and a key theme of this special issue of Weed Science, is that herbicide resistance is a wicked problem that is, in many ways, unsolvable. We introduced this notion in an earlier manuscript (Ervin and Jussaume 2014), but develop this argument in detail here. One way to understand this dilemma may be to contrast wicked with tame problems. For Batie (2008), tame problems are those where there is a clear definition of a problem, the outcome is true or false (black or white), the problem is static, and the task is completed when the problem is solved. Examples include "determining the specific source of a food contamination outbreak; identifying the cost effectiveness of different crop practices to reduce soil erosion, or determining the costs and benefits of expanding an irrigation project" (Batie 2008).

Wicked problems are far more complex and difficult for society to address. The concept of wicked problems is far from new, but perhaps has begun to enter scientific discourse more frequently in recent years as the scientific community begins to recognize that many of the more intractable societal problems it is being called upon to address are more likely to be wicked than tame. Some of the early thinking on wicked problems comes from the urban planning literature, as planners were faced with the challenge of developing and managing urban systems that were complex, integrated, and required constant upgrades and changes in the face of increasing population pressure. One such early conceptualization posited 10 characteristics of wicked problems (Rittel and Webber 1973). We will use a brief review of those characteristics to help 
the reader better understand the wickedness of the herbicide resistance challenge.

\section{Characteristics of Wicked Problems}

\section{Wicked Problems Have No Definitive Formula-} tion. The first characteristic of a wicked problem is that such problems have no definitive formulation. A wicked problem has no single or easy-to-identify cause, and thus implies a high level of uncertainty in understanding the problem and proposing solutions. For example, one of the challenges facing health-care reform is that no single policy prescription (such as limiting Medicaid reimbursements) will address all the complex issues surrounding the distribution and cost of health care. In the case of herbicide resistance, although there does appear to be an emerging consensus that the herbicide resistance problem is associated with a lack of diversity in weed control tactics (Norsworthy et al. 2012; Price et al. 2011; Shaw et al. 2012; Vencill et al. 2012), there is no consensus as to why some growers do not diversify their tactics. Indeed, the no-definitive-formulations characteristic would suggest to us that growers vary in their actions and rationales. Overuse of a single chemistry, lack of rotation programs, lack of other effective options, difficulty in using other tools, time constraints facing farm operators, higher costs of alternatives, weather conditions preventing selection of other choices, fragile soils that prevent tillage as an option, bundling of genetics that create a sense of requirement to use the technology, and prevalence of resistant plants in neighboring fields have all been suggested as contributing to the problem. In addition, any diverse set of tactics for dealing with herbicide resistance will need to address a variety of local factors, such as the type of weed, the type(s) of known resistance, local climatic conditions, and so on. In other words, weed management is a wicked problem because there are multiple causes, and thus potential solutions will need to accommodate the particulars of each field, each weed species, each farmer, and each area or community.

Wicked Problems Have No Stopping Rule. The second characteristic of a wicked problem is that such problems have no stopping rule. In other words, there is no end date or point to the problem. In the case of endangered species protection, whether a species is rebounding requires constant monitoring, and even if a species develops a minimal stable population, it does not mean that, at some point, the species could never again become endangered. In the case of weed resistance, it is clear that farmers will always need to evaluate and adapt their weed management (and other pest management) strategies constantly because weed resistance(s) will constantly develop and evolve. There is no particular herbicide chemistry that can be developed that will permanently eliminate a plant that has been determined to be a weed. Of special note here are the recognized incidences of metabolic resistance, wherein weeds have demonstrated the ability to metabolize herbicides to which they have never been exposed. This may be the case with rigid ryegrass in Australia. The evolution of resistance will never be stopped, and there will be a constant need to adapt and develop new weed management strategies.

Wicked Problems Have No True or False Solutions. The third characteristic of a wicked problem is that there is no true/false solution. Drought mitigation efforts can be used to illustrate this characteristic. Clearly, reduction of water use by various actors can be part of a strategy to address water shortages. However, reduction alone may be insufficient, and each group of actors (for example: farmers, industrial users, homeowners) will face costs associated with reduced water access. In addition, some groups may face greater costs than others. In other words, loss of water access may be more costly (or bad) for some groups. Similarly, almost every good weed management strategy has costs, including the likelihood that if the strategy is adopted on a wide enough scale, weeds will evolve resistance to the use of that strategy. Conversely, the possibility of ineffective tactics may exist, but how poorly they perform may depend on perspective as well as the extent and type of weed resistance problem being addressed. An example of a comparatively bad tactic could be the use of an herbicide mix that utilizes multiple modes of action (MOA), when in fact only one of the herbicides used in the mix is effective on the target species. Other examples would be the use of tillage without understanding the biology of the target species, or the use of cover crops in arid regions where it is not viable to use water on a crop that cannot provide an immediate cash income. In other words, the extent of how good or bad a solution is for addressing a wicked problem will vary according to local context, economic parameters, social costs, etc.

There Is No Ultimate Test for Deriving A Solution. The next two characteristics of a wicked 
problem flow from the recognition that wicked problems have no fixed cause(s) and no true/false answers. Because of these conditions, wicked problems have no ultimate test of a solution, and yet every solution is a "one-shot operation" (Rittel and Webber 1973). Addressing climate change is perhaps the ultimate example of these characteristics, in part because climate change is but a single case. Reducing $\mathrm{CO}_{2}$ emissions may be necessary, but in and of itself will not address climate change and can never be "tested," at least not in the way that scientific experiments are tested. Similarly, developing a new MOA for combating herbicideresistant weed species may be important, but will never be the ultimate answer that can be tested, can be implemented, and will lead to a permanent resolution of the problem. Indeed, it has always been clear that successful weed management approaches need to be diverse, multiple, and constantly changing. One only needs to look at the surveys of most common and troublesome weeds in various states over the past six decades to note that weeds that were not even considered problematic years ago are now topping these lists today, whereas those that were the most troublesome 30 yr ago no longer appear on these lists, not to mention that the types of resistance that these species have developed has been constantly changing (Webster and Nichols 2012).

Wicked Problems Have No Fixed Set of Solutions. Given these conditions, it is understandable that wicked problems "do not have an enumerable set of potential solutions" (Rittel and Webber 1973). It is impossible to determine if all of the potential solutions have been identified, in part because there are so many possible causes and solutions, and because of the importance of using "judgment" in selecting potential solutions in different settings. Approaches for managing weed resistance are constantly being developed, such as exploring new crop genetics to use existing chemistries in new ways, or the burning of crop residue and the grinding of harvest chaff (Walsh et al. 2013). More research about the biology of weeds will be constantly needed in order to target weaknesses, such as the deep tillage work that Culpepper has done to bury and destroy Palmer amaranth (Culpepper et al. 2010). There are also potential solutions that may be "discovered" in the future by either scientists or growers, and there are solutions that eventually lose their effectiveness. In other words, there will never be an exhaustive list, or toolbox, of potential solutions that will be finalized for addressing weed resistance.

Each Wicked Problem Is Essentially Unique. Another characteristic of wicked problems is that "every wicked problem is essentially unique" (Rittel and Webber 1973). This does not suggest that it is not possible to learn from other wicked problems, but it does emphasize that each wicked problem must be addressed on its own terms. Thus, the use of refuges in integrated insect management, which has been relatively easy to implement, does not appear to be transferrable to integrated weed management, in part because the biology of weeds is different. Nonetheless, the notion of an integrated approach makes sense in both insect and weed management, but it is necessary to understand each wicked problem in its own right and to develop an appropriate strategy for continuously evaluating and responding to each.

Each Wicked Problem Is Symptomatic of Another Wicked Problem. The eighth characteristic identified by Rittel and Webber is that "every wicked problem can be considered to be a symptom of another problem." Thus, it appears that rising carbon dioxide levels that are associated with the wicked problem of climate change are likely to alter the efficacy of herbicides in controlling invasive weed species (Ziska 2014). One could also imagine that the agricultural wicked problem of managing nitrogen use, which has been linked to algae blooms, could be interconnected with the wicked problem of weed resistance, depending on whether and/or how different farm inputs may affect the efficacy of one another. Perhaps another way of describing this characteristic is to wonder whether any and all wicked problems (for example, weed management, nutrient management, water management, etc.) in agriculture are linked together and are part of a larger wicked problem of farm management. As average size of farm operation continues to grow, farm operators look to reduce their labor inputs, and yet many integrated management approaches require more, and not less, management time and quality. Thus, the spread of the use of management systems that relied heavily on the use of glyphosate was associated with an increase in the adoption of reduced tillage production systems as well as lowering labor requirements in agriculture, both of which made it easier for farm operations to continue to grow in size. These benefits may begin to unravel with the need to adopt more integrated farm management systems that involve a more 
diverse array of practices and more intensive use of management expertise and labor, thus leading to a need to develop holistic management systems that recognize how subcomponents of that system are interconnected.

Wicked Problems Have Multiple Potential and Viable Causes. The ninth characteristic of a wicked problem is that such problems have multiple potential and viable causes. So, in trying to explain pandemics such as the Spanish influenza of the last century, it would be possible to highlight causes such as living and sanitary conditions, the origin of the disease, the rate at which that disease mutated, and so on. Similarly, some may ask what are the causes, and perhaps some might wonder, who was ultimately "responsible" for the rapid evolution of weed resistance to herbicides? Was it the use of a particular herbicide, or the use of seeds that enabled the widespread use of a certain herbicide, or was it the reduction in the number of viable commercial crops that encouraged this evolutionary trajectory? And, was this connected to the reduction in the number of viable commercial crops due in large part to federal support programs for certain crops? In some cases, the process may have begun with the heavy reliance on a single chemistry that was extremely effective, leading growers to displace past practices, but over time a variety of factors emerge as contributing to the evolution of weed resistance, and oftentimes, the factors that weigh heavily in the case of one weed or trait may not be useful in explaining other cases of weed resistance. Also, not only is it difficult to identify a single cause, but the selection of any single cause can be arbitrary and may limit our ability to recognize that there were multiple causes, some of which may be unknown, and multiple potential solutions, all of which will need to be considered over time.

Those Who Propose Solutions to Wicked Problems Can't Afford to Be Wrong. Finally, and perhaps the most telling characteristic of a wicked problem, is that the person proposing solutions to the wicked problem "has no right to be wrong" (Rittel and Webber 1973). Indeed, one of the more intriguing contradictions arising in contemporary society is that our ability to understand just how many of our problems are wicked may be inversely correlated with our unwillingness to accept that some specific answer, some magic bullet, may not be able to solve that problem. Regardless of whether the problem is climate change, solvency of the social security system, providing clean drinking water, or addressing weed resistance, there is always public pressure to find simple solutions to problems, when in reality wicked problems require continuing study and evaluation. Wicked problems demand a neverending process of readdressing a problem with multiple possible solutions. Such approaches do not fit well in a public discourse that demands immediate and permanent answers, and that puts pressure on those proposing solutions not to be wrong.

Hopefully, this discussion of 10 characteristics of wicked problems helps us to appreciate the challenges facing those who need to find approaches to the growing problem of herbicide resistance. Such an appreciation has profound implications for how to structure and deliver education, technical assistance, and incentive and regulatory programs on herbicide resistance. Simply relying on traditional, top-down approaches that have often been used by universities, government, industry, and commodity organizations will not suffice. In particular, more emphasis on integrating the human and social dimensions with the biological, physical, and technological aspects will be crucial for making progress (Ervin and Jussaume 2014). To that end, we now present some principles that should be considered parts of approaches for addressing the wicked problem of herbicide resistance.

\section{Principles to Negotiate Wicked Problems}

It should be clear to the reader that a fixed and definitive model for developing solutions for managing weed resistance to herbicides does not and cannot exist. Because there are multiple causes of weed resistance, because various ways of studying and understanding are necessary to understand the full dimensions of the problem, and because there is no optimal, definitive set of solutions for all farms, the only option is to develop a continually evolving set of strategies that will vary by

- Place (ecosystem setting)

- Specific weed(s)

- Crop or rotation

- Community or region

- Other salient biophysical, technical, and social factors

Recognizing this complexity is an absolutely essential first step. Continuing to treat $H R$ as a tame problem for which farmers can implement a set of BMPs from a general technical manual will in 
all likelihood not stem the exponential increase in HR. But that raises the question of what approach will be effective in addressing $\mathrm{HR}$ as a wicked problem. Some guidance exists on the conditions that, when followed, are most likely to result in progress in addressing wicked problems associated with agriculture and conservation issues (Sayer et al. 2013). The 10 principles endorsed by some international scientific and management bodies, such as the Convention on Biological Diversity, to deal with agricultural land use change and conservation are now presented. It is important to emphasize that the principles are not a blueprint to follow, but that they can be used as part of a strategy to outline a constructive approach. Also, they do not have a one-to-one correspondence with the 10 wicked problem characteristics. Importantly, the principles are based on a landscape approach that is essential to address the weed mobility and common pool resource aspects of weed resistance. A brief discussion of each principle illustrates its relevance to managing $\mathrm{HR}$.

Principle 1: Continual Learning and Adaptive Management. As we have noted in the previous section, herbicide resistance can never be eliminated, just controlled. Therefore, weed management must be a never-ending search to understand the complex set of relationships that can affect the evolutionary path of resistance. Moreover, the search will vary over biophysical and social settings as the nature of herbicide resistance as a wicked problem dictates. Both passive and active adaptive management can be used to experiment with old and new approaches that may work in specific sets of biophysical and social circumstances. The learning and adaptive management principle may invoke both technical and social or institutional mechanisms, including new forms of collaboration that will be necessary when significant weed mobility is present. An initial learning exercise may be to survey the extent of perceived and actual resistance on lands in the community to establish a baseline to assess management options.

Principle 2: Common Concern Entry Point. A critical early step is to find a common concern that all stakeholders share in the particular herbicide resistance issue. It might be economic, environmental, or social in nature. Identifying this common concern will help build trust among those who must participate in the collaborative effort. Trust can be enhanced when objectives and values are shared openly. Initiating this process by focusing on reachable intermediate targets may give the participants a beginning foundation for ongoing collaboration. For example, stakeholders may agree that cleaning harvest equipment of weed seed is an essential first step to slow the spread of resistant weeds. Or, it may be that eliminating weeds from public roadside ditches that can spread to private farmland is in the community's perceived common interest.

Principle 3: Multiple Scales. Understanding the diverse set of influences and constraints at different scales that influence management approaches is a crucial step. Examples for herbicide resistance may include community social norms of farming, efforts of regional crop advisers, sales or incentive programs of agricultural chemical companies, and federal policies, such as crop insurance schemes that cover yield declines due to $H R$. If growers become frustrated that their on-farm efforts are not producing the intended impacts because of countervailing external forces, including the actions of external public- and private-sector actors, farmers may abandon otherwise constructive practices. As Sayer et al. (2013) note "An awareness of these higher and lower level processes can improve local interventions, inform higher-level policy and governance, and help coordinate administrative entities." Noted scholars have emphasized the need to formulate multiple-scale approaches for common pool resource management when such feedback effects and synergies exist (e.g., Ostrom 2007).

Principle 4: Multifunctionality. Agricultural landscapes provide multiple goods and services that extend beyond food and energy production, for example, wildlife habitat, water regulation, greenhouse gas sequestration, aesthetic beauty, and cultural identity. Each use is valued in different ways by different sets of stakeholders, which sets the stage for potential conflict as increasing some uses may decrease the provision of other services (Nelson et al. 2009). In other words, agricultural production and the resolution of its problems, such as herbicide resistance, involves more than farmers and their support networks. Recognizing the tradeoffs among differing land uses and stakeholder interests should occur early in the HR management process to assure that all relevant stakeholders are engaged in problem definition before formulating adaptive management options. For example, this might entail creating local weed management boards with representatives from groups, including those not involved in agriculture, who have a stake in HR control. 
Principle 5: Multiple Stakeholders. This principle is the logical outcome of principle 4-different sets of people receive different goods and services from the management of agricultural lands. Therefore, identifying the diverse stakeholders to agricultural land-use issues becomes an essential step if effective adaptive management approaches are to be devised and implemented.

Failure to engage all of the relevant parties in the problem definition and decision-making processes will lead to suboptimal, and sometimes unethical, outcomes (Sayer et al. 2013). The form of engagement can vary depending upon the particular situation. One approach may be to use focus groups to inventory the range of values involved and the significance of impacts across different groups. The need to recognize all affected parties does not imply that each must be an active participant in the negotiated solution. For problems with large and diverse stakeholder groups, the transaction costs of finding a consensus management approach acceptable to all may be prohibitive (Sayer et al. 2013). As an example, downstream water users may be affected if farmers use more tillage to combat herbicide resistance, but not all of these water users need to be engaged in the decision process if those stakeholders accept that a state or federal environmental management agency is responsibly protecting their interests.

Principle 6: Negotiated and Transparent Change Logic. Establishing a climate of trust is essential to any good-faith negotiation process. It is no different for finding an acceptable herbicide resistance management strategy by a particular community. Building the basis for trust can begin with the identification of a common entry concern as articulated in principle 2 . As with that foundational principle, openness and transparency are crucial to establishing a shared vision and agreement on goals and process that engenders trust. Another is the full involvement of stakeholders to give legitimacy to the process. There may be specific aspects of trust for herbicide resistance management. One might be an institution devised by all participants to monitor each actor's compliance with agreed-to management practices (Ostrom et al. 2012). Similarly, a transparent mechanism for instituting sanctions if compliance is not achieved builds trust that one farmer's herbicide resistance actions will be matched by her neighbors or penalties will be imposed. The sanctions define the risks of noncooperation and motivate all farmers in the community to play a constructive and collaborative role in the management approach.

Principle 7: Clarification of Rights and Responsibilities. Parallel to the design principles for sustainable common pool resource management (Ostrom et al. 2012), the rights and responsibilities of all parties to the wicked problem need to be clearly defined (Sayer et al. 2013). Without such clarity, the opportunities for individual actions to conflict with achieving the end goal could multiply and subvert any collaborative effort. This specification of rights and responsibilities also requires an effective and equitable justice system to resolve inevitable conflicts. That system of conflict resolution need not necessarily be public, as private organizations to manage common pool resources have shown. Indeed, a recent trend in natural resource management has been the clear specification of rights and responsibilities by private individuals and groups, in lieu of top-down prescriptive regulations by government. This type of approach allows flexibility for the parties to negotiate options to address the wicked problem that fit the particular situation. An example in the realm of herbicide resistance might be the establishment of a community-based organization that sets up rules for performance outcomes, such as a maximum percentage of field area with resistant weeds, with corresponding sanctions for violations.

Principle 8: Participatory and User-Friendly Monitoring. Two design principles for effective common pool resource management are broad participation by resource appropriators and a monitoring system accountable to those appropriators (Ostrom et al. 2012). These principles share a strong resemblance to participatory and userfriendly monitoring for negotiating wicked problem approaches.

A potential advantage of following this principle is the sharing of tacit and explicit knowledge of some of the herbicide resistance causes and impacts that can inform adaptive management options. In facilitating this information sharing, the validity of producer and other stakeholder knowledge systems are mutually recognized and perhaps arbitrated. An institutional design challenge for herbicide resistance is to facilitate user-friendly and accurate monitoring that rewards the stakeholders for being truthful, even when the monitoring data could reveal problems on their own lands. Without this incentive, growers may not report early indications 
of spreading resistance that could thwart effective management by the entire community.

Principle 9: Resilience. As explained, herbicide resistance is a never-ending wicked problem with no stopping rule. That is, the degree of resistance can be controlled but not abated. As long as farmers continue to suppress weeds though chemical or biological herbicides, or mechanical or cultural means, weeds will evolve resistance through natural selection that will end up reducing the effectiveness of those practices. Therefore, actions and conditions that enhance the capacity of the agro-ecological system to recover after unplanned biophysical, economic, and social perturbations will be necessary to foster resilience. In other words, a broader view of time and context is required. For example, one characteristic of resilient weed control systems is employing a diversity of tactics. It can be argued that the exponentially growing weed resistance to glyphosate was in large measure the result of a lack of diversity in weed control tactics, as well as in crops grown, by so many growers. In the long run, fostering resilient agroecosystems has demonstrable net benefits. However, the short-run benefits of predominantly using glyphosate have apparently overwhelmed growers consideration of long-term risks and benefits. As for facilitating effective monitoring, some form of behavioral or institutional change needs to reward growers for overcoming short-term barriers. That could include some type of incentive or insurance scheme to foster a longer-term perspective, or some form of private or public regulation to require more diversity.

\section{Principle 10: Strengthened Stakeholder Capaci-} ty. A recurrent theme in these principles is the need to involve all key stakeholders if wicked problems are to be navigated successfully. Importantly, the stakeholders who require this strengthened capacity extend beyond producers to chemical industry representatives, crop advisers, government personnel, university researchers and educators, and public interest groups. Developing stakeholder capacity to participate effectively in this exploration of discovery will require an explicit investment. The land grant university system has a strong record through the state extension services of building capacity through education and technical assistance programs. Many, if not most of those programs, however, have concentrated on nonsocial technical recommendations drawn from fields like biology, mechanical engineering, and agricultural sciences. Although these aspects remain vital to discovering effective approaches to managing herbicide resistance, they are insufficient to address this wicked problem. Building other forms of social capacity will be just as vital. An example might be the skills to participate effectively in collaborative community efforts, and to assume leadership roles in local institutions. This will require a reorientation of traditional extension education to include training programs that build human and social capacities necessary to tackle the wicked HR problem.

These 10 principles represent a minimal set of essential strategies that could be utilized to address many wicked problems that characterize agricultural land use issues. Implementing the principles will be challenging for several reasons. Given the pervasive uncertainty that surrounds wicked problems, one could suppose that either a precautionary or adaptive management strategy may be appropriate. However, commentators have noted that even those approaches can rely too heavily on technical science and miss the critical role of heterogeneous cultural values (Blaint et al. 2011). Unless those values are recognized and interwoven into the search for constructive approaches from the outset, progress is unlikely.

\section{Implications for Research and Action}

Weed resistance is a rapidly escalating problem that defies easy solutions. The responses to this problem will necessarily be never ending and require an understanding of the perceptions and behaviors of human actors, in addition to the use of a variety of technological and cultural options. To demonstrate why managing weed resistance should be viewed as a wicked problem, we presented 10 characteristics of wicked problems as they relate to weed resistance. We then reviewed 10 principles of resource management that need to be considered when developing and implementing weed management approaches in the context of addressing a wicked problem.

When taken together, these characteristics of wicked problems and principles of resource management suggest a number of implications for future research on weed resistance and for practical strategies designed to address weed resistance in the field. Foremost amongst these implications is for all parties to recognize that there will never be a final, or magic bullet solution to the problem of weed resistance. New chemical modes of action, for instance, can be an important part of the weed management toolbox. However, such tools will 
never be sufficient and will never interrupt the evolution of weeds in response to human activity.

Additionally, we hope our review underscores how weed resistance is as much a human, or social, problem as it is a problem related to plant biology. Humans adopt weed management tactics that weeds evolve to, and are impacted by the ways in which that evolutionary process unfolds. Weed resistance as a social problem means that many actors influence, and are affected by, weed resistance, and thus that all actors must come to recognize the problem and become involved in the responses. This includes farm households, those who support farm households in the private sector, public actors, and nonprofit organizations that have a stake in agriculture and the impacts of agricultural practices. It will be particularly important for nonlocal actors to understand the important role of local actors in understanding weed resistance and developing management approaches, because weed management issues vary so greatly by locality. It is only at each local level that the unique aspects of weed resistance in a particular region can be understood, and where community participation to address weed resistance must be developed.

The recognition that biological, physical, technological, and social factors interact to cause herbicide resistance implies that all of those must be considered as part of developing management approaches. Although it is highly likely that weed scientists will play a significant role in efforts to control resistance, the complex nature of wicked problems makes clear that approaches developed by weed scientists will not succeed without their collaboration in interdisciplinary teams that include scientists from other disciplines as well as relevant stakeholders from outside the scientific community. Recent evidence of the dramatic growth in the number of resistant weeds supports this conclusion. Interdisciplinary approaches have the greatest chance for success, and must be structured in ways that all disciplines interact from problem definition forward. When some key disciplines are left out of the early tasks, the problem likely will be framed inappropriately, and program resources spent unwisely.

As the principles emphasize, adaptive management, stakeholder involvement, and multiple objectives must guide approaches to control the spread of resistance. This will require new research and extension capacity building in the human and institutional dimensions of weed management programs. Some of the examples we have used illustrate this fundamental shift in the nature of education and technical assistance. If mobility of weed seed and pollen is a significant factor in spreading resistance, then common pool resource management must be addressed. Research around the world has documented that community-based approaches that follow certain design principles can be the most sustainable approach (Ostrom et al. 2012). Engaging the community stakeholders in that process will likely require contributions from the social sciences, including sociology, economics, anthropology, and even psychology. Therefore, these disciplines must be integrally involved in the development and delivery of education and technical assistance programs on resistance, if they are to be effective.

In summary, implementing integrated weed management programs based on these principles will require significant institutional changes in the public and private sectors. We have already hinted at the nature of those changes for traditional extension programs, such as moving to more interdisciplinary team approaches and involving all stakeholders from the outset. Perhaps the pivotal aspect to innovate landscape approaches will be a shift from project-oriented actions to processoriented activities (Sayer et al. 2013). This shift runs counter to predominant university and industry weed management strategies based largely on finding new chemistries or technologies for projects to "solve" farmers' resistance problems. In a process-oriented approach, the emphasis "... tends away from such top-down engineered solutions toward more bottom-up negotiated actions that emerge from a process akin to muddling through" (Sayer et al. 2013). In doing so, it ties the stakeholders to long-term iterative processes, granting them responsibilities and empowerment.

The reforms in institutions to foster such approaches can be led by university administrators and business leaders with strong appeals from stakeholder groups. Once they understand that the old education and technical assistance tactics are not working, a teachable moment opens for HR wicked problems and the principles to address them effectively. Progress toward this institutional change will take time, as stakeholder pressures, likely from ecological and economic damages, have to build to change course. Such a shift in approach is likely easier for government, university, and nongovernmental organizations than the business sector that is often driven by short-term objectives. Of course, tremendous inertia often exists in the public and 
nonprofit 'sectors to changing their modes of operation as well. Progress on interdisciplinary programs remains stubbornly slow in most universities because of internal reward systems, e.g., promotion and tenure, that favor disciplinary discoveries. Despite some growth over the last two decades, federal research and education funding to support such efforts is limited.

Nongovernmental organizations, such as conservation bodies, may be in the best position to push the landscape approach, as Sayer et al. (2013) relate. However, none of the conservation organizations currently appear to have the interest and capacity to address herbicide resistance management. That could change if the problem continues to accelerate and poses widespread environmental risks. Further, the major foundations operating in agriculture worldwide appear to still favor silver bullet technologies rather than complementing them with people-based initiatives.

We should not totally discount the potential role of industry. Evidence shows that competitive businesses must be responsive to their customers if they wish to be sustainable. One can hypothesize that new entrepreneurs will identify the need for process-based approaches to herbicide resistance management and fill that market niche with farm and landscape advisory services if the potential for profit exists. Farm and crop advisory companies would seem obvious candidates to assume this role as they hear the needs of farmers firsthand. One can even imagine such a process-based enterprise could be attractive to some herbicide manufacturers if they perceive the new services will extend the useful life and market of their weed control technologies. However, the successful development and application of those services will entail collaborations with all stakeholders, as the principles make clear. That extra time and cost may deter some firms from entering the new market.

These closing points make clear that the decisionmaking process for weed management will need to become more inclusive and complex than in the past. This is both an exciting and a formidable challenge for weed scientists, who have traditionally worked closely with individual farmers and their cropping advisers. An additional challenge will be for all parties concerned to accept that all weed management approaches will need to be iterative and adaptive, and that creativity, patience, and perseverance will be needed.

\section{Acknowledgments}

The authors would like to extend their sincere gratitude to the members of the herbicide-resistance task force that convened two national summits sponsored by the Weed Science Society of America and co-hosted by the National Research Council. We are indebted to the task force members and to Kara Laney and Robin Schoen of the NRC for the many insightful intellectual discussions that they have engaged in with us over the years. We would also like to thank the Editors of Weed Science, and the anonymous reviewers, for their valuable insights and feedback. We would also like to acknowledge the support we have received as part of the USDAAFRI supported project on "Integrating Human Behavior \& Agronomic Practices to Improve Food Security by Reducing the Risk \& Consequences of Herbicide-Resistance Weeds".

\section{Literature Cited}

Batie S (2008) Wicked problems and applied economics. Am J Appl Econ 90:1176-1191

Blaint P, Stewart R, Desai A, Walters L (2011) Wicked Environmental Problems: Managing Uncertainty and Conflict. $272 \mathrm{p}$

Culpepper AS, Kichler J, Sosnoskie L, York A, Sammons D, Nichols B (2010) Integrating cover crop residue and moldboard plowing into glyphosate-resistant Palmer amaranth management programs. Page 1650 in Proceedings of the 2010 Beltwide Cotton Conference. New Orleans, LA: National Cotton Council of America

Edwards C, Jordan D, Owen M, Dixon P, Young B, Wilson R, Weller S, Shaw D (2014) Benchmark study on glyphosateresistant crop systems in the United States. Economics of herbicide resistance management practices in a 5-year fieldscale study. Pest Manage Sci 70:1924-1929

Ervin D, Jussaume R (2014) Herbicide resistance: integrating social science into understanding and managing weed resistance and associated environmental impacts. Weed Sci 62:403-414

Fenichel E, Richards T, Shanafelt D (2014) The control of invasive species on private property with neighbor-to-neighbor spillovers. Environ Res Econ 59:231-255

Foresman C, Glasgow L (2008) Grower perceptions and experiences with glyphosate resistant weeds. Pest Manage Sci 64:388-391

Heap I (1997) The International Survey of Herbicide Resistant Weeds. http://www.weedscience.org. Accessed April 29, 2015

Llewellyn R, Allen D (2006) Expected mobility of herbicide resistance via weed seeds and pollen in a Western Australian cropping region. Crop Prot 25:520-526

McCoy N, Amatya P (2005) Games people play: human behavior and invasive weed management. Rangelands 27:8-14

Nelson E, Mendoza G, Regetz J, Polasky S, Tallis H, Cameron DR, Chan KM, Daily GC, Goldstein J, Kareiva PM, Lonsdorf E, Naidoo R, Ricketts T, Shaw MR (2009) Modeling multiple ecosystem services, biodiversity conservation, commodity 
production, and tradeoffs at landscape scales. Front Ecol Environ 7:4-11

Norsworthy JK, Ward SM, Shaw DR, Llewellyn RS, Nichols RL, Webster TM, Bradley KW, Frisvold G, Powles SB, Burgos N, Witt WW, Barrett M (2012). Reducing the risks of herbicide resistance: best management practices and recommendations. Weed Sci 60(sp1):31-62

Ostrom E (2007) A diagnostic approach for going beyond panaceas. Proc Natl Acad Sci USA 104:15181-15187

Ostrom E, Chang C, Pennington M, Tarko V (2012) The Future of the Commons: Beyond Market Failure and Government Regulation. London, UK: Institute for Economic Affairs. $104 \mathrm{p}$

Owen M, Boerboom C (2004) National Glyphosate Stewardship Forum. St. Louis, MO. $80 \mathrm{p}$

Price AJ, Balkcom KS, Culpepper SA, Kelton JA, Nichols RL, Schomberg H (2011) Glyphosate-resistant Palmer amaranth: a threat to conservation tillage. J Soil Water Conserv 66:265275

Rittel H, Webber M (1973) Dilemmas in a general theory of planning. Policy Sci 5:155-169

Sayer J, Sunderland T, Ghazoul J, Pfund J-L, Sheil D, Meijaard E, Venter M, Boedhihartono AG, Day M, Garcia C, van Ooster C, Buck LE (2013) Ten principles for a landscape approach to reconciling agriculture, conservation, and other competing land uses. Proc Natl Acad Sci USA 110:8349-8356
Shaw D, Culpepper SA, Owen M, Price AJ, Wilson R (2012) Herbicide-resistant weeds threaten soil conservation gains: finding a balance for soil and farm sustainability. Issue Paper 49. Ames, IA: CAST.

Vencill WK, Nichols RL, Webster TM, Soteres JK, MallorySmith C, Burgos NR, Johnson WG, McClelland MR (2012) Herbicide resistance: toward an understanding of resistance development and the impact of herbicide-resistant crops. Weed Sci 60(sp1):2-30

Walsh M, Newman P, Powles S (2013) Targeting weed seeds incrop: a new weed control paradigm for global agriculture. Weed Technol 27:431-436

Webster TM, Nichols RL (2012) Changes in the prevalence of weed species in the major agronomic crops of the southern United States: $1994 / 1995$ to $2008 / 2009$. Weed Sci 60:145157

Ziska L (2014) Climate, $\mathrm{CO}_{2}$ and invasive weed management. Pp 293-304 in Ziska L, Dukes J, eds. Invasive Species and Global Climate Change. Boston: CABI

Received July 29, 2015, and approved February 15, 2016.

Associate Editor for this paper: Sarah Ward, Colorado State University. 